\title{
Farklı Tuz Konsantrasyonlarının Bazı Tritikale Hatlarının Çimlenmesi Üzerine Etkileri
}

\author{
Ramazan DOĞAN, Emine BUDAKLI ÇARPICI* \\ Uludağ Üniversitesi, Ziraat Fakültesi, Tarla Bitkileri Bölümü, Bursa
}

Geliş (Received): 16.02.2016

Kabul (Accepted): 25.03.2016

\begin{abstract}
ÖZET: $\mathrm{Bu}$ araştırma, bazı tritikale hat ve çeşitlerinin çimlenme döneminde farklı tuz konsantrasyonlarına tepkilerinin belirlenmesi amacıyla laboratuvar koşullarında yürütülmüştür. Denemede bitki materyali olarak Nörtingen, Eronga ve Karma-2000 tritikale çeşitleri ile C9, N X 2003-3, NX2002-2, N X 2003-12, N X E-3, 2003 X 2002-10 ve 2003 X 2002-8 tritikale hatları kullanılmıştır. Çalışmada beş farklı $\mathrm{NaCl}$ dozu $(0,50,100,150$ ve 200 $\mathrm{mM}$ ) ele alınmıştır. Araştırmada, tohumlarda 12. ve 24. saatlerdeki su alım oranları, çimlenme oranları, plumula uzunluğu, radikula uzunluğu, plumula ve radikula kuru ağılıkları gibi özellikler incelenmiştir. Elde edilen sonuçlar tuz uygulamalarının incelenen tüm özellikleri olumsuz etkilediğini göstermiştir. Çeşit ve hatların tuz stresine tepkileri incelenen tüm özellikler bakımından farklı olmuştur. Çeşit/hat $\mathrm{x}$ tuz interaksiyonu ise sadece çimlenme yüzdesi ve plumula uzunluğu açısından önemli çıkmıştır. Araştırmada ele alınan hatlar arasında N X E-3 ve N X 2003-12 hatları çimlenme döneminde diğerlerine oranla tuz stresine toleranslı bulunmuş̧tur.
\end{abstract}

Anahtar Kelimeler: Tritikale, hat, tuz konsantrasyonu, çimlenme dönemi

\section{Effects of Different Salt Concentration on Germination of Some Triticale Lines}

ABSTRACT: This study was conducted to determine the responses of some triticale varieties and lines to salt stress at germination stage. Triticale varieties and lines Nörtingen, Eronga, Karma-2000, C9, N X 2003-3, NX2002-2, N X 2003-12, N X E-3, 2003 X 2002-10 and 2003 X 2002-8 were used as plant materials. Five different salt stress levels $(0,50,100,150$ and $200 \mathrm{mM})$ were applied in this study. The parameter examined were water intake rate of seeds at 12 and 24 h., germination percentage, plumule length, radicle length, plumule and radicle dry weights. The results obtained indicated that salt treatments affected negatively all of the parameters examined. The responses of variety/lines to salt stress were different in respect of all parameters. Variety/lines x salt interactions were significant only for germination percentage and plumule length. N X E-3 and N X 2003-12 lines responded to bemore resistant to salt stress than the other genotypes examined at germination stage.

Key Words: Triticale, line, salt concentration, germination stage

\section{GIRIŞ}

Tarımı yapılan alanlarda verimliliği etkileyen faktörlerden birisi tuzluluktur. Dünyada sulanabilir tarım arazilerinin yaklaşık üçte birinde tuzluluk sorunu olup bu alanın yaklaşık 400-950 milyon ha olduğu tahmin edilmektedir (Hasegawa ve ark. 1986; Özkaldı ve ark. 2004). Tuzluluk nedeniyle dünyada her y1l 10 milyon ha arazi elden çıkmaktadır. Özellikle kurak ve yarı kurak iklim bölgelerinde yetersiz yağış ve yüksek buharlaşma tuzluluğun başlıca nedenlerindendir. Diğer taraftan sulamadaki yanlış uygulamalar, özellikle iyi bir drenajın olmadığı alanlarda tuzluluğa neden olabilmektedir (Baltacı ve ark. 2004). Çimlenme döneminde farklı tritikale çeşit ve hatlarının tuza dayanıklılıklarına ilişkin yapılan çalışmalarda tuz konsantrasyonlarının çeşit ve hatlar üzerinde olumsuz etkilerinin olduğu tespit edilmiştir. Atak ve ark. (2006), üç farklı tritikale çeşidinin 2.4, 4.2, 5.9, 7.7, 10.6 ve $13.2 \mathrm{dS} \mathrm{m}^{-1}$ elektriksel iletkenliğe sahip tuz konsantrasyonlarındaki çimlenme yüzdesi, fide yaş ve kuru ağırlıklarını incelemişlerdir. Araştırıcılar, artan tuz konsantrasyonlarına bağlı olarak çimlenme yüzdesinin azaldığını, bu durumunda düşük su alım oranından çok biriken aşırı $\mathrm{Na}$ iyonunun etkisinden kaynaklandığını bildirmişlerdir. Kara ve ark. (2011) tritikalede çimlenme ve fide gelişimi üzerine tuz konsantrasyonlarının etkisini belirlemek amacıyla yaptıkları bir çalışmada Karma-2000 çeşidi ve CIMMYT kaynaklı tritikale hatları deneme materyali olarak kullanılmışlardır. Araştırıcılar kontrol ve EC değeri 3.9, 6.1, 8.3, 10.5, 14.9, 19.3, 25.0 dS m ${ }^{-1}$ olan tuz konsantrasyonlarını ele almışlardır. Araştırma sonucunda tüm çeşit ve hatlarda tuz konsantrasyonu arttıkça çimlenme oranının da azaldığı tespit edilmiștir.

$\mathrm{Bu}$ çalışma Uludağ Üniversitesi Ziraat Fakültesi Tarla Bitkileri Bölümü'nde melezleme çalışmaları sonucunda elde edilmiş ve adaptasyon denemeleri ile ümitvar olduğu tespit edilmiş olan tritikale hatlarının çimlenme döneminde farklı tuz konsantrasyonlarındaki tepkilerini incelemek amacıyla yürütülmüştür.

\section{MATERYAL ve METOT}

Araştırma Uludağ Üniversitesi Ziraat Fakültesi Tarla Bitkileri Bölümü Bitki Fizyolojisi Laboratuvarında 2014 yllında yürütülmüştür. Denemede Nörtingen, Eronga ve Karma-2000 tritikale çeşitleri ile Uludağ Üniversitesi Ziraat Fakültesi Tarla Bitkileri bölümünde yürütülen melezleme çalışmaları sonucunda ümitvar oldukları tespit edilen C9, N X 2003-3, NX2002-2, N X 2003-12, N X E-3, 2003 X 2002-10 ve 2003 X 2002-8 tritikale hatları kullanılmıştır. Çalışmada 5 farklı tuz konsantrasyonu $(0,50,100,150$ ve $200 \mathrm{mM})$ ele 
alınmıştır. Tuz konsantrasyonlarına ait EC değerleri sirasiyla $0.0024 \mathrm{dS} \mathrm{m}^{-1}, 5.34 \mathrm{dS} \mathrm{m}^{-1}, 10.33 \mathrm{dS} \mathrm{m}^{-1}$, $15.12 \mathrm{dS} \mathrm{m}^{-1}$ ve $19.92 \mathrm{dS} \mathrm{m}^{-1}$ dir. Araştırma tesadüf parselleri deneme desenine göre üç tekerrürlü olarak yürütülmüştür. Denemede çimlendirme öncesinde her bir hatta ait tohumlar yüzey steralizasyonuna tabi tutulmuştur. $\mathrm{Bu}$ amaçla \%1'lik sodyum hipoklorit kullanılmıştır. Tohumlar $3 \mathrm{dk}$ sodyum hipoklorit ile çalkalanmış ve ardından saf su ile iyice yıkanmıştır (Akbarimoghaddam ve ark. 2011). Yüzey sterilizasyonu yapılan tohumlar kurutma kağıtları üzerine alınarak kurutulmuş ve ardından içerisinde çift katlı filtre kağıdı bulunan petri kaplarına $(15 \mathrm{~cm}$ çapında $)$ yerleştirilmiştir. Çift katlı filtre kağıtları arasına konulan tohumların üzerine $15 \mathrm{ml}$ farklı tuz yoğunlukları içeren solüsyonlar konulmuştur. Her bir petri kabına 30 tohum konulmuştur. Petri kaplarında tuz birikimini engellemek amacıyla 2 gün aralıklarla filtre kağıtları değiştirilmiş (Rehman ve ark., 1996; Kaymakanova, 2009; Atak ve ark., 2006) ve ardından tekrar $15 \mathrm{ml}$ solüsyon verilmiştir. Farklı tuz konsantrasyonlarının bazı tritikale hatlarının çimlenmeleri üzerine etkilerini belirlemek amacıyla tohumlar petri kaplarında 8 gün karanlık koşullardaki iklimlendirme dolabında $25 \pm 1^{\circ} \mathrm{C}$ sıcaklıkta tutulmuş ve her gün çimlenen tohumlar sayılmıştır. Gözlemler her gün aynı saatte yapılmış ve kök uzunluğu $1 \mathrm{~mm}$ geçen tohumlar çimlenmiş olarak kabul edilmiştir(Atak ve ark., 2006; Kara ve ark., 2011). Araştırmada tohumların ilk 12. ve 24. saatlerdeki su alım oranlarını (SAO) tespit etmek amacıyla aşağıda verilen eşitlikten yararlanılmıştır.

$\% \mathrm{SAO}=(\mathrm{A} 2-\mathrm{A} 1 / \mathrm{A} 1) 100($ Akbarimoghaddam ve ark. 2011).

A1 = Tohumun ilk ağırlığ

$\mathrm{A} 2=12$. veya 24 . saatteki tohum ağırlığ

Denemede çimlenmenin 8. gününde çeşit ve hatların çimlenme yüzdeleri (ÇY) belirlenmiş ve ardından her bir petri kabından 10 sürgün örnek olarak alınmış ve bu örneklerde plumula uzunluğu (PU) ve radikula uzunluğu (RU) ölçülmüştür. Plumula kuru ağırlığı (PKA) ve radikula kuru ağırlığının (RKA) belirlenmesi için 8 . günün sonunda alınan sürgünler plumula ve radikula kısımlarına ayrılmış ve $70{ }^{\circ} \mathrm{C}$ 'de 48 saat kurutulup tartılmıştır. Denemeden elde edilen veriler tesadüf parselleri deneme desenine uygun olarak varyans analizine tabi tutulmuşlardır. Bütün hesaplamalar bilgisayarda MINITAB ve MSTAT-C paket programlarından faydalanılarak yapılmıştır. Farklı grupların belirlenmesinde Asgari Önemli Fark (AÖF) testinden yararlanılmıştır.

\section{BULGULAR ve TARTISMA}

Bazı tritikale çeşit ve hatlarının farklı tuz konsantrasyonlarındaki 12 . ve 24 . saatteki su alım oranları, çimlenme yüzdeleri, plumula uzunlukları, radikula uzunlukları, plumula ve radikula kuru ağırlıklarına ilişkin varyans analiz sonuçları Çizelge 1'de verilmiştir. Çeşit/hatlar ile tuz konsantrasyonlarıarasında incelenen tüm özellikler bakımından istatistiki anlamda \% 1 olasılık düzeyinde farklılıklar ortaya çıkmıştır. Çeşit/hat $x$ tuz konsantrasyonu interaksiyonu bakımından çimlenme yüzdesinde $\% 5$, plumula uzunluğunda ise $\% 1$ olasıllk düzeyinde önemli farklılıklar tespit edilmiştir (Çizelge $1)$.

12. ve 24. Saatteki Su Alım Oranları (\%):İlk 12 saat sonunda en yüksek su alım oranı \% 51.98 ile Eronga, en düşük su alım oranı ise \% 44.26 ile Karma 2000 çeşidinde tespit edilmiştir (Çizelge 2). Tuz konsantrasyonlarının 12. saatteki su alım oranı üzerine etkisi negatif yönde olmuş ve tuz konsantrasyonlarındaki artışa bağlı olarak su alım oranı da azalmıştır. Bunun sonucunda da 12. saat sonunda en yüksek su alım oranı kontrolden elde edilirken, en düşük değer ise \% 45.61 ile en yüksek tuz konsantrasyonundan $(200 \mathrm{mM}$ ) elde edilmiştir (Çizelge 2). 24. saatteki su alım oranı bakımından, N X 2003-3 hattı \% 65.93 su alım oranı ile en yüksek değere ulaşırken, Karma-2000 çeşidi ise \% 59.03 oranıly son sırada yer almıştır. Tuz konsantrasyonları incelendiğinde ise en düşük konsantrasyonda en yüksek su alım oranı elde edilmiştir (Çizelge 3). Artan tuz konsantrasyonları ortamın osmatik basıncını arttırmış ve bu da tohumların su alım oranını düşürmüştür. Bu olay başka araştırıcılar tarafından da rapor edilmiştir. Nitekim,Maas ve Hoffman (1977) ile Basalah (1991) yüksek tuz seviyesinden dolayı iyon dengesinin ve osmotik dengenin bozulması sonucu tohumların su alımlarının azaldığını bildirmişlerdir. Atak ve ark. (2006) ise bazı tritikale çeşitlerinde su alım oranının tuz konsantrasyonundan etkilenmediğini, tohumların ilk 6 saat içinde çok daha hızlı su alımı yaptıklarını rapor etmişlerdir. 12. ve 24. saatteki su alım oranları bakımından çeşit/hat $\mathrm{x}$ tuz konsantrasyonu interaksiyonunun etkisi önemsiz çıkmıştır (Çizelge 1).

Çimlenme Yüzdesi (\%):Çimlenme yüzdesi bakımından çeşit/hatlar arasındaki farklılıklar \% 1 olasılık düzeyinde çok önemli bulunmuş ve en yüksek çimlenme yüzdesi N X E-3 hattından, en düşük çimlenme yüzdesi ise 2003 X 2002-10 hattından elde edilmiştir (Çizelge 1 ve Çizelge 4). Artan tuz konsantrasyonlarına bağlı olarak çimlenme yüzdesi giderek azalmıştır. En yüksek çimlenme yüzdesi kontrolde, en düşük çimlenme yüzdesi ise $200 \mathrm{mM}$ tuz konsantrasyonunda tespit edilmiştir (Çizelge 1 ve Çizelge 4).

Çimlenme yüzdeleri gerek çeşit/hat gerekse tuz konsantrasyonlarına göre farklılık göstermiş ve bu farklılaşmalar interaksiyon etkilerinde de ortaya çıkmıştır. Çizelge 4'ten de görüleceği gibi, N X 200312 , N X E-3, 2003 X 2002-10, 2003 X 2002-8 ve N X 2003-3 hatlarında en yüksek çimlenme yüzdeleri (\%100) tuzsuz koşullarda, Karma-2000 çeşidinde ise \% 100 çimlenme 0 ve $50 \mathrm{mM}$ tuz konsantrasyonlarında 
ortaya çımıştır (Çizelge 4). Bulgularımız; genotiplerinartan tuz konsantrasyonlarına bağlı olarak çimlenme yüzdelerinin azaldığını bildiren birçok araştırıcının bulguları ile benzerlik göstermiştir (Akgün ve ark., 2011; Kara ve ark., 2011).

Plumula Uzunluğu (cm):Tritikalegenotipleri arasında plumulauzunlğu bakımından önemli farklılıklar ortaya çıkmıştır. En uzun plumulaNörtingen çeşidinde, en kısa plumula ise Eronga çeşidi ile C9 hattında tespit edilmiştir. Artan tuz konsantrasyonları sonucunda plumula önemli ölçüde kısalmış ve kontrole göre 200
$\mathrm{mM}$ tuz konsantrasyonunda plumulauzunluğunda \% 71.5 azalma olmuştur (Çizelge 1 ve Çizelge 5).Plumula uzunluğu bakımından çeşit/hat $x$ tuz konsantrasyonuinteraksiyonu önemli çıkmış ve bunun sonucunda da çeşit/hatları içerisinde NXE-3 tritikale hattı $14.24 \mathrm{~cm}$ değer ile $0 \mathrm{mM}$ tuz konsantrasyonunda en uzun plumulaya sahip olurken, C9 tritikale hattı ise $2.18 \mathrm{~cm}$ ile $200 \mathrm{mM}$ tuz konsantrasyonunda en düşük değere sahip olmuştur (Çizelge 5). Benzer sonuçlar Kara ve ark. (2011) tarafindan da tespit edilmiştir.

Çizelge 1. Farklı Tuz Konsantrasyonlarının Bazı Tritikale Çeşit ve Hatlarında İncelenen Bazı Özelliklere İlişkin Varyans Analiz Sonuçları (K.O.)

\begin{tabular}{|c|c|c|c|c|c|c|c|c|}
\hline $\begin{array}{c}\text { Varyasyon } \\
\text { Kaynağ1 }\end{array}$ & SD & 12. SAO & 24. SAO & ÇY & PU & RU & PKA & RKA \\
\hline Çeşit/Hat (A) & 9 & $102.303^{* *}$ & $77.20^{* *}$ & $72.40^{* *}$ & $6.551^{* *}$ & $7.394^{* *}$ & $8.735^{* *}$ & $6.7793^{* *}$ \\
\hline Tuz Kons. (B) & 4 & $216.439^{* *}$ & $1283.98^{* *}$ & $277.52^{* *}$ & $515.193^{* *}$ & $478.413^{* *}$ & $114.83^{* *}$ & $8.5872^{* *}$ \\
\hline A x B & 36 & 7.724 & 17.49 & $21.97^{*}$ & $1.212^{* *}$ & 2.010 & 1.350 & 0.6596 \\
\hline Hata & 100 & 9.696 & 13.30 & 12.77 & 0.658 & 1.392 & 0.907 & 0.6032 \\
\hline
\end{tabular}

12. SAO: 12. Saatteki su alım oranı, 24 SAO: 24. Saatteki su alım oranı, ÇY: çimlenme yüzdesi, PU: plumula uzunluğu, RU:radikula uzunluğu, PKA: plumula kuru ağırlığı, RKA: radikula kuru ağırlığı

*,** Sirasıyla 0.05 ve 0.01 olasıllk düzeylerinde istatistiki olarak önemlidir.

Çizelge 2. Bazı Tritikale Çeşit ve Hatlarının Farklı Tuz Konsantrasyonlarına Ait 12. Saatteki Su Alım Oranları (\%)

\begin{tabular}{|c|c|c|c|c|c|c|}
\hline \multirow{2}{*}{ Çeşit/Hat } & \multicolumn{5}{|c|}{ Tuz Konsantrasyonu (mM) } & \multirow{2}{*}{ Ortalama } \\
\cline { 2 - 6 } & 0 & 50 & 100 & 150 & 200 & \\
\hline C9 & 52.51 & 48.49 & 46.43 & 47.06 & 45.21 & $47.94 \mathrm{~cd}$ \\
\hline N X 2003-3 & 56.90 & 50.61 & 50.20 & 49.66 & 48.40 & $51.16 \mathrm{ab}$ \\
\hline Eronga & 57.10 & 53.34 & 51.06 & 48.03 & 49.74 & $51.98 \mathrm{a}$ \\
\hline Nörtingen & 52.20 & 44.30 & 42.71 & 45.51 & 45.72 & $46.09 \mathrm{~d}-\mathrm{f}$ \\
\hline NX2002-2 & 52.17 & 50.53 & 48.04 & 48.07 & 48.55 & $49.47 \mathrm{bc}$ \\
\hline N X 2003-12 & 48.46 & 45.83 & 43.74 & 44.94 & 41.99 & $44.99 \mathrm{ef}$ \\
\hline Karma 2000 & 47.75 & 43.46 & 44.48 & 43.55 & 42.05 & $44.26 \mathrm{f}$ \\
\hline N X E-3 & 52.60 & 45.65 & 47.56 & 45.57 & 42.08 & $46.69 \mathrm{de}$ \\
\hline 2003 X 2002-10 & 47.59 & 44.90 & 45.79 & 47.62 & 45.18 & $46.22 \mathrm{~d}-\mathrm{f}$ \\
\hline 2003 X 2002-8 & 56.48 & 49.84 & 48.95 & 44.90 & 47.13 & $49.46 \mathrm{bc}$ \\
\hline Ortalama & $52.44 \mathrm{a}$ & $47.70 \mathrm{~b}$ & $46.90 \mathrm{bc}$ & $46.49 \mathrm{bc}$ & $45.61 \mathrm{c}$ & \\
\hline
\end{tabular}

Çeşit/hatlar ve tuz konsantrasyonlarına ait önemli çıkan ortalamalarda aynı harfi taşıyan değerler arasında 0.05 olasılık düzeyinde fark yoktur.

Çizelge 3. Bazı Tritikale Çeşit ve Hatlarının Farklı Tuz Konsantrasyonlarına Ait 24. Saatteki Su Alım Oranları (\%)

\begin{tabular}{|c|c|c|c|c|c|c|}
\hline \multirow{2}{*}{ Çeşit/Hat } & \multicolumn{7}{|c}{ Tuz Konsantrasyonu (mM) } & \multirow{2}{*}{ Ortalama } \\
\cline { 2 - 6 } C9 & 0 & 50 & 100 & 150 & 200 & \\
\hline N X 2003-3 & 67.48 & 65.40 & 65.51 & 56.21 & 57.85 & $62.49 \mathrm{~cd}$ \\
\hline Eronga & 72.45 & 72.76 & 66.00 & 61.23 & 57.19 & $65.93 \mathrm{a}$ \\
\hline Nörtingen & 76.50 & 67.89 & 61.33 & 60.44 & 59.84 & $65.20 \mathrm{ab}$ \\
\hline NX2002-2 & 73.06 & 63.71 & 57.58 & 57.35 & 52.30 & $60.26 \mathrm{de}$ \\
\hline N X 2003-12 & 76.79 & 65.19 & 60.71 & 58.04 & 54.80 & $63.11 \mathrm{bc}$ \\
\hline Karma 2000 & 67.30 & 61.60 & 59.06 & 55.40 & 51.80 & $59.03 \mathrm{e}$ \\
\hline N X E-3 & 72.15 & 63.16 & 60.02 & 58.68 & 54.28 & $61.66 \mathrm{c}-\mathrm{e}$ \\
\hline 2003 X 2002-10 & 67.24 & 62.82 & 59.07 & 59.38 & 51.09 & $59.22 \mathrm{~d}-\mathrm{e}$ \\
\hline 2003 X 2002-8 & 73.05 & 71.12 & 64.34 & 53.02 & 54.99 & $63.31 \mathrm{a}-\mathrm{c}$ \\
\hline Ortalama & $71.64 \mathrm{a}$ & $65.94 \mathrm{~b}$ & $61.75 \mathrm{c}$ & $57.95 \mathrm{~d}$ & $55.11 \mathrm{e}$ & \\
\hline
\end{tabular}

Çeşit/hatlar ve tuz konsantrasyonlarına ait önemli çıkan ortalamalarda aynı harfi taşıyan değerler arasında 0.05 olasılık düzeyinde fark yoktur. 
Çizelge 4. Bazı Tritikale Çeşit ve Hatlarının Farklı Tuz Konsantrasyonlarına Ait Çimlenme Yüzdeleri (\%)

\begin{tabular}{|c|c|c|c|c|c|c|}
\hline \multirow{2}{*}{ Çeşit/Hat } & \multicolumn{5}{|c|}{ Tuz Konsantrasyonu (mM) } & \multirow{2}{*}{ Ortalama } \\
\cline { 2 - 6 } & 0 & 50 & 100 & 150 & 200 & \\
\hline C9 & $96.67 \mathrm{a}-\mathrm{e}$ & $95.33 \mathrm{a}-\mathrm{f}$ & $95.44 \mathrm{a}-\mathrm{f}$ & $94.18 \mathrm{~b}-\mathrm{g}$ & 76.671 & $91.66 \mathrm{f}$ \\
\hline N X 2003-3 & $99.00 \mathrm{ab}$ & $98.89 \mathrm{a}-\mathrm{c}$ & $96.67 \mathrm{a}-\mathrm{e}$ & $95.56 \mathrm{a}-\mathrm{f}$ & $86.67 \mathrm{~h}$ & $95.36 \mathrm{~b}-\mathrm{d}$ \\
\hline Eronga & $96.67 \mathrm{a}-\mathrm{e}$ & $96.67 \mathrm{a}-\mathrm{e}$ & $93.33 \mathrm{~b}-\mathrm{g}$ & $93.11 \mathrm{c}-\mathrm{g}$ & $92.22 \mathrm{~d}-\mathrm{h}$ & $94.40 \mathrm{c}-\mathrm{e}$ \\
\hline Nörtingen & $97.78 \mathrm{a}-\mathrm{d}$ & $95.44 \mathrm{a}-\mathrm{f}$ & $95.33 \mathrm{a}-\mathrm{f}$ & $93.00 \mathrm{~d}-\mathrm{g}$ & $92.11 \mathrm{~d}-\mathrm{h}$ & $94.73 \mathrm{~b}-\mathrm{e}$ \\
\hline NX2002-2 & $94.45 \mathrm{a}-\mathrm{g}$ & $92.22 \mathrm{~d}-\mathrm{h}$ & $91.11 \mathrm{e}-\mathrm{h}$ & $91.11 \mathrm{e}-\mathrm{h}$ & $92.22 \mathrm{~d}-\mathrm{h}$ & $92.22 \mathrm{ef}$ \\
\hline N X 2003-12 & $100.00 \mathrm{a}$ & $100.00 \mathrm{a}$ & $95.56 \mathrm{a}-\mathrm{f}$ & $95.56 \mathrm{a}-\mathrm{f}$ & $94.22 \mathrm{a}-\mathrm{g}$ & $97.07 \mathrm{ab}$ \\
\hline Karma 2000 & $100.00 \mathrm{a}$ & $98.89 \mathrm{a}-\mathrm{c}$ & $96.67 \mathrm{a}-\mathrm{e}$ & $95.56 \mathrm{a}-\mathrm{f}$ & $93.33 \mathrm{~b}-\mathrm{g}$ & $96.89 \mathrm{a}-\mathrm{c}$ \\
\hline N X E-3 & $100.00 \mathrm{a}$ & $98.89 \mathrm{a}-\mathrm{c}$ & $98.89 \mathrm{a}-\mathrm{c}$ & $98.89 \mathrm{a}-\mathrm{c}$ & $97.78 \mathrm{a}-\mathrm{d}$ & $98.89 \mathrm{a}$ \\
\hline 2003 X 2002-10 & $100.00 \mathrm{a}$ & $95.56 \mathrm{a}-\mathrm{f}$ & $95.56 \mathrm{a}-\mathrm{f}$ & $90.00 \mathrm{f}-\mathrm{h}$ & $88.89 \mathrm{gh}$ & $94.00 \mathrm{~d}-\mathrm{f}$ \\
\hline 2003 X 2002-8 & $100.00 \mathrm{a}$ & $97.56 \mathrm{a}-\mathrm{d}$ & $93.22 \mathrm{~b}-\mathrm{g}$ & $92.11 \mathrm{~d}-\mathrm{h}$ & $91.11 \mathrm{e}-\mathrm{h}$ & $94.80 \mathrm{~b}-\mathrm{e}$ \\
\hline Ortalama & $98.46 \mathrm{a}$ & $96.95 \mathrm{ab}$ & $95.18 \mathrm{bc}$ & $93.91 \mathrm{c}$ & $90.52 \mathrm{~d}$ & \\
\hline
\end{tabular}

Çeşit/hatlar, tuz konsantrasyonları ve çeşit/hat $\mathrm{x}$ tuz konsantrasyonu interaksiyonlarına ait önemli çıkan ortalamalarda aynı harfi taşıyan değerler arasında 0.05 olasılık düzeyinde fark yoktur.

Çizelge 5. Bazı Tritikale Çeşit ve Hatlarının Farklı Tuz Konsantrasyonlarına Ait Plumula Uzunlukları (cm)

\begin{tabular}{|c|c|c|c|c|c|c|}
\hline \multirow{2}{*}{ Çeşit/Hat } & \multicolumn{5}{|c|}{ Tuz Konsantrasyonu (mM) } & \multirow{2}{*}{ Ortalama } \\
\cline { 2 - 6 } & 0 & 50 & 100 & 150 & 200 & \\
\hline C9 & $13.19 \mathrm{a}-\mathrm{c}$ & $12.33 \mathrm{c}-\mathrm{f}$ & $10.13 \mathrm{~h}$ & $6.13 \mathrm{k}$ & $2.18 \mathrm{n}$ & $8.79 \mathrm{~d}$ \\
\hline N X 2003-3 & $13.12 \mathrm{a}-\mathrm{d}$ & $12.92 \mathrm{~b}-\mathrm{e}$ & $11.18 \mathrm{f}-\mathrm{h}$ & 8.621 & 4.681 & $10.10 \mathrm{a}-\mathrm{c}$ \\
\hline Eronga & $13.68 \mathrm{ab}$ & $11.75 \mathrm{e}-\mathrm{g}$ & $7.761 \mathrm{j}$ & $6.58 \mathrm{jk}$ & $3.06 \mathrm{~m}-\mathrm{n}$ & $8.57 \mathrm{~d}$ \\
\hline Nörtingen & $13.85 \mathrm{ab}$ & $14.03 \mathrm{ab}$ & $12.32 \mathrm{c}-\mathrm{f}$ & 8.711 & $3.491-\mathrm{n}$ & $10.48 \mathrm{a}$ \\
\hline NX2002-2 & $13.81 \mathrm{ab}$ & $13.86 \mathrm{ab}$ & $10.22 \mathrm{~h}$ & $7.511 \mathrm{j}$ & $4.061 \mathrm{~m}$ & $9.89 \mathrm{bc}$ \\
\hline N X 2003-12 & $14.07 \mathrm{ab}$ & $14.12 \mathrm{ab}$ & $11.83 \mathrm{~d}-\mathrm{g}$ & 8.121 & $4.071 \mathrm{~m}$ & $10.44 \mathrm{ab}$ \\
\hline Karma 2000 & $14.12 \mathrm{ab}$ & $13.77 \mathrm{ab}$ & $10.32 \mathrm{~h}$ & $6.48 \mathrm{jk}$ & 4.551 & $9.85 \mathrm{c}$ \\
\hline N X E-3 & $14.24 \mathrm{a}$ & $13.65 \mathrm{ab}$ & $11.411-\mathrm{h}$ & 8.041 & 4.571 & $10.38 \mathrm{a}-\mathrm{c}$ \\
\hline 2003 X 2002-10 & $13.34 \mathrm{a}-\mathrm{c}$ & $13.50 \mathrm{a}-\mathrm{c}$ & $10.93 \mathrm{~g}-\mathrm{h}$ & $7.411-\mathrm{k}$ & $4.041 \mathrm{~m}$ & $9.84 \mathrm{c}$ \\
\hline 2003 X 2002-8 & $14.16 \mathrm{ab}$ & $13.17 \mathrm{a}-\mathrm{c}$ & $11.25 \mathrm{f}-\mathrm{h}$ & $7.45 \mathrm{j}$ & 4.501 & $10.11 \mathrm{a}-\mathrm{c}$ \\
\hline Ortalama & $13.76 \mathrm{a}$ & $13.31 \mathrm{~b}$ & $10.74 \mathrm{c}$ & $7.51 \mathrm{~d}$ & $3.92 \mathrm{e}$ & \\
\hline
\end{tabular}

Çeşit/hatlar, tuz konsantrasyonları ve çeşit/hat $\mathrm{x}$ tuz konsantrasyonu interaksiyonlarına ait önemli çıkan ortalamalarda aynı harfi taşıyan değerler arasında 0.05 olasılık düzeyinde fark yoktur.

Radikula Uzunluğu (cm):Radikula uzunluğu açısından çeşit/hatlar arasında önemli farklılıklar ortaya çıkmış ve en uzun radikula uzunluğu NXE-3 hattından elde edilmiştir. Tuz konsantrasyonlarındaki artış radikula uzunluğunu olumsuz etkilemiş ve bunun sonucunda da en kisa radikulalar $200 \mathrm{mM}$ tuz konsantrasyonundan elde edilmiștir (Çizelge 1 ve Çizelge 6). Tuza dayanımda önemli göstergelerden biri radikulanın gelişme durumudur. Çimlenme sırasında su alımında tuz engeli yoksa kökçük normal gelişim gösterir. $\mathrm{Bu}$ nedenle tuz stresi nedeniyle kökçük gelişiminde ortaya çıkan gerilemeler, bitkinin su alımındaki azalmalardan kaynaklanmaktadır. Tuzun radikula uzunluğu üzerindeki olumsuz etkisi birçok araștırı tarafından da tespit edilmiştir (Atak ve ark., 2006; Kara ve ark., 2011). Çeşit/hat $x$ tuz konsantrasyonu interaksiyonunun radikula uzunluğu üzerine etkisi önemsiz olmuş ve radikula uzunlukları 5.04-19.55 cm arasında değișmiștir (Çizelge 1 ve Çizelge 6).
Plumula ve Radikula Kuru Ăgırlı̆̆ı (mg):Çeşit/hatlar arasında en yüksek plumula kuru ağırlıkları N X E-3 ve 2003 X 2002-10 hatlarından, en yüksek radikula kuru ağırlığı ise 2003 X 2002-10 hattından elde edilmiștir. Artan tuz konsantrasyonlarınınplumula ve radikula kuru ağırlıkları üzerindeki etkileri olumsuz yönde olmuş ve tuz konsantrasyonu arttıkça kuru ağırlıklarda da azalmalar ortaya çıkmıştır. Ancak tuz konsantrasyonarındaki artış plumula gelişimini radikulaya oranla daha fazla etkilemiştir (Çizelge 7 ve Çizelge 8). Bu durum, Atak ve ark. (2006); Moud ve Mahgsoudi, (2008); Akbarimoghaddam ve ark., (2011); Bahrani ve HaghJoo, (2012)'nun çalışmalarında belirttikleri tuz konsantrasyonundaki artışa, köklere göre sürgünlerin daha hassas olduğu bulgusu ile paralelik göstermektedir. Çeşit/hat $\mathrm{x}$ tuz konsantrasyonuinteraksiyonununplumula ve radikula kuru ağırlığı üzerine etkisi önemsiz olmuş ve genel olarak plumula kuru ağırlıkları 3.07-11.43 mg, radikula kuru ağırlıkları ise 6.40-10.47 mg arasında değişmiştir (Çizelge 1, Çizelge 7 ve Çizelge 8). 
Çizelge 6. Bazı Tritikale Çeşit ve Hatlarının Farklı Tuz Konsantrasyonlarına Ait Radikula Uzunlukları (cm)

\begin{tabular}{|c|c|c|c|c|c|c|}
\hline \multirow{2}{*}{ Çeşit/Hat } & \multicolumn{5}{|c|}{ Tuz Konsantrasyonu (mM) } & \multirow{2}{*}{ Ortalama } \\
\cline { 2 - 6 } & 0 & 50 & 100 & 150 & 200 & \\
\hline C9 & 17.19 & 14.91 & 12.27 & 9.53 & 5.04 & $11.79 \mathrm{~b}-\mathrm{c}$ \\
\hline N X 2003-3 & 15.53 & 15.08 & 12.81 & 9.21 & 6.29 & $11.78 \mathrm{~b}-\mathrm{c}$ \\
\hline Eronga & 15.24 & 13.49 & 10.59 & 8.77 & 6.98 & $11.02 \mathrm{c}-\mathrm{d}$ \\
\hline Nörtingen & 16.88 & 16.14 & 13.21 & 9.60 & 6.57 & $12.48 \mathrm{ab}$ \\
\hline NX2002-2 & 17.72 & 15.90 & 10.95 & 9.91 & 6.59 & $12.22 \mathrm{ab}$ \\
\hline N X 2003-12 & 16.90 & 14.85 & 12.99 & 10.17 & 7.24 & $12.43 \mathrm{ab}$ \\
\hline Karma 2000 & 17.67 & 14.81 & 12.83 & 9.73 & 7.71 & $12.55 \mathrm{ab}$ \\
\hline N X E-3 & 19.55 & 15.88 & 12.03 & 10.28 & 7.56 & $13.06 \mathrm{a}$ \\
\hline 2003 X 2002-10 & 15.96 & 12.61 & 9.89 & 8.59 & 6.92 & $10.80 \mathrm{~d}$ \\
\hline 2003 X 2002-8 & 15.54 & 14.51 & 11.88 & 9.54 & 7.59 & $11.81 \mathrm{bc}$ \\
\hline Ortalama & $16.82 \mathrm{a}$ & $14.82 \mathrm{~b}$ & $11.95 \mathrm{c}$ & $9.53 \mathrm{~d}$ & $6.85 \mathrm{e}$ & \\
\hline
\end{tabular}

Çeşit/hatlar ve tuz konsantrasyonlarına ait önemli çıkan ortalamalarda aynı harfi taşıyan değerler arasında 0.05 olasılık düzeyinde fark yoktur.

Çizelge 7. Bazı Tritikale Çeşit ve Hatlarının Farklı Tuz Konsantrasyonlarına Ait Plumula Kuru Ağırlıkları (mg)

\begin{tabular}{|c|c|c|c|c|c|c|}
\hline \multirow{2}{*}{ Çeşit/Hat } & \multicolumn{7}{|c}{ Tuz Konsantrasyonu (mM) } & \multirow{2}{*}{ Ortalama } \\
\cline { 2 - 6 } & 0 & 50 & 100 & 150 & 200 & \\
\hline C9 & 9.10 & 8.47 & 8.40 & 6.20 & 3.07 & $7.05 \mathrm{~d}$ \\
\hline N X 2003-3 & 8.70 & 8.43 & 7.70 & 7.00 & 5.33 & $7.43 \mathrm{~cd}$ \\
\hline Eronga & 9.73 & 8.53 & 7.40 & 6.87 & 3.73 & $7.25 \mathrm{~cd}$ \\
\hline Nörtingen & 11.00 & 10.60 & 9.47 & 7.27 & 4.20 & $8.51 \mathrm{ab}$ \\
\hline NX2002-2 & 8.80 & 8.37 & 7.27 & 6.07 & 5.23 & $7.15 \mathrm{~d}$ \\
\hline N X 2003-12 & 8.90 & 9.50 & 8.53 & 6.90 & 5.37 & $7.84 \mathrm{bc}$ \\
\hline Karma 2000 & 11.10 & 9.83 & 7.90 & 7.43 & 5.83 & $8.42 \mathrm{ab}$ \\
\hline N X E-3 & 10.83 & 10.90 & 9.67 & 7.67 & 6.17 & $9.05 \mathrm{a}$ \\
\hline 2003 X 2002-10 & 11.43 & 10.87 & 9.00 & 8.80 & 5.20 & $9.06 \mathrm{a}$ \\
\hline 2003 X 2002-8 & 8.60 & 8.57 & 8.50 & 7.40 & 5.57 & $7.73 \mathrm{~cd}$ \\
\hline Ortalama & $9.82 \mathrm{a}$ & $9.41 \mathrm{a}$ & $8.38 \mathrm{~b}$ & $7.16 \mathrm{c}$ & $4.97 \mathrm{~d}$ & \\
\hline
\end{tabular}

Çeşit/hatlar ve tuz konsantrasyonlarına ait önemli çıkan ortalamalarda aynı harfi taşıyan değerler arasında 0.05 olasılık düzeyinde fark yoktur.

Çizelge 8. Bazı Tritikale Çeşit ve Hatlarının Farklı Tuz Konsantrasyonlarına Ait Radikula Kuru Ağırlıkları (mg)

\begin{tabular}{|c|c|c|c|c|c|c|}
\hline \multirow{2}{*}{ Çeşit/Hat } & \multicolumn{7}{|c}{ Tuz Konsantrasyonu (mM) } & \multirow{2}{*}{ Ortalama } \\
\cline { 2 - 6 } & 0 & 50 & 100 & 150 & 200 & \\
\hline C9 & 9.50 & 8.23 & 8.63 & 8.23 & 6.60 & $8.24 \mathrm{bc}$ \\
\hline N X 2003-3 & 8.33 & 7.83 & 7.93 & 7.87 & 7.00 & $7.79 \mathrm{c}-\mathrm{e}$ \\
\hline Eronga & 7.13 & 6.50 & 6.67 & 6.90 & 6.40 & $6.72 \mathrm{f}$ \\
\hline Nörtingen & 8.30 & 8.07 & 8.13 & 7.13 & 7.35 & $7.80 \mathrm{c}-\mathrm{e}$ \\
\hline NX2002-2 & 7.97 & 7.50 & 6.93 & 7.07 & 6.93 & $7.28 \mathrm{ef}$ \\
\hline N X 2003-12 & 7.43 & 7.40 & 7.43 & 7.27 & 6.87 & $7.28 \mathrm{ef}$ \\
\hline Karma 2000 & 8.83 & 7.80 & 7.70 & 7.93 & 7.67 & $7.99 \mathrm{~cd}$ \\
\hline N X E-3 & 9.30 & 9.17 & 8.30 & 8.00 & 8.17 & $8.59 \mathrm{ab}$ \\
\hline 2003 X 2002-10 & 10.47 & 10.27 & 8.83 & 8.67 & 6.90 & $9.03 \mathrm{a}$ \\
\hline 2003 X 2002-8 & 8.33 & 7.70 & 7.73 & 7.37 & 7.13 & $7.65 \mathrm{de}$ \\
\hline Ortalama & $8.56 \mathrm{a}$ & $8.05 \mathrm{~b}$ & $7.83 \mathrm{bc}$ & $7.64 \mathrm{c}$ & $7.10 \mathrm{~d}$ & \\
\hline
\end{tabular}

Çeşit/hatlar ve tuz konsantrasyonlarına ait önemli çıkan ortalamalarda aynı harfi taşıyan değerler arasında 0.05 olasılık düzeyinde fark yoktur.

\section{SONUÇ}

$\mathrm{Bu}$ çalışmada farklı tuz konsantrasyonlarının bazı tritikale hatlarının çimlenmesi üzerine etkileri araştırılmıştır. Araştırma sonuçları, artan tuz konsantrasyonlarının incelenen tüm karakterler üzerine istatistiki olarak önemli düzeyde fakat olumsuz etki yaptı̆̆ını göstermiştir. Araştırmada, çeşit/hat $\mathrm{x}$ tuz konsantrasyonunun çimlenme yüzdesi ve plumula uzunluğu üzerindeki etkisi önemli çıkmıştır. Özellikle plumula uzunluğu açısından tuz konsantrasyonlarındaki artış başlangıçta pumula gelişimini yavaş yavaş etkilemiş, ancak tuz konsantrasyonu $150 \mathrm{mM}$ olduğunda 
plumula uzunluğu önemli ölçüde azalma göstermiştir. Tritikale hatları açısından ölçülen tüm özellikler dikkate alındığında bunlar içerisinde tuz stresine tolerans açısından çok kararlı olanlara rastlanılmamış olmakla birlikte, bazı hatların birçok özellik açısından istikrarlı oldukları görülmüştür. N X E-3 ve N X 2003-12 hatları bu bakımdan öne çıkmışlardır. Bununla birlikte daha sağlıklı önerilerde bulunabilmek için bu araştırmaların çimlenme dönemi ile birlikte fide dönemlerini de kapsayacak şekilde yürütülmesi gerekir.

\section{KAYNAKLAR}

Akbarimoghaddam, H., Galavi, M., Ghanbari A. Panjehkeh, N. 2011. Salinity Effects on Seed Germination and Seedling Growth of Bread Wheat Cultivars. Trakia Journal of Sciences, 9 (1): 43-50.

Akgün, I., Kara, K., Altındal, D. 2011. Effect of Salinity $(\mathrm{NaCl})$ on Germination, Seedling Growth and Nutrient Uptake of Different Triticale Genotypes. Turkish J. Field Crops, 2011, 16 (2): 225-232.

Atak, M., Kaya, M.D., Kaya, G., Kıllı, Y., Ciftci, C.Y. 2006. Effects of $\mathrm{NaCl}$ on the Germination,Seedling Growth and Water Uptake of Triticale. Turkish J. Agric. Foresty, 30: 39-47.

Bahrani, A., Hagh Joo, M. 2012. Response of Some Wheat (Triticum aestivum L.) Genotypes to Salinity at Germination and Early Seedling Growth Stages. World App. Sci. J., 16 (4): 599-609.

Baltac1, F., Can, D., Karaoğlu, A., Tantur, A. 2004 Tuzluluk, Nedenleri ve Çevresel Etkileri, Sulanan Alanlarda Tuzluluk Yönetimi Sempozyumu, 20-21 Mayıs, Ankara, s:185-190.
Basalah, M. O. 1991. Effect of Soaking on Seed Germination and Growth of Sequash (Cucurbita реро L) Seeding. Arab Gulf J Scient Res. 9:87-97.

Hasegawa, P.M, Bressan, R.A., Handa, A.V. 1986. Cellular Mechanism of Salinity Tolerance. Hort. Science, 21 (6):1317-1324.

Kara, B., Akgün, İ., Altındal, D. 2011 Tritikale Genotiplerinde Çimlenme ve Fide Gelişimi Üzerine Tuzluluğun $(\mathrm{NaCl})$ Etkisi. Selçuk Tarım ve Gıda Bilimleri Derg., 25 (1): 1-9.

Kaymakanova, M. 2009. Effect of Salinity on Germination and Seed Physiology in Bean (Phaseolus vulgaris L.). Biotechnol. \& Biotechnol. EQ. 23/326-329.

Maas, E.V., Hoffman, .J. 1977. Crop Salt Tolerance Current Assessment. Journal of the Irrigation and Drainage Division, 103(2):115-134.

Moud, A. M., Maghsoudi, K. 2008. Salt Stress Effects on Respiration and Growth of Germinated Seeds of Different Wheat (Triticum aestivum L.) Cultivars. World Journal of Agricultural Sciences 4 (3): 351 358

Özkaldı, A., Boz, B., Yazıcı, V. 2004. GAP'ta Drenaj Sorunları ve Çözüm Önerileri. Sulanan Alanlarda Tuzluluk Yönetimi Sempozyumu, 20-21 Mayıs, Ankara s: 97-105.

Rehman, S., Harris, P.J.C., Bourne, W.F., Wilkin, J.. 1996. The Effect of Sodium Chloride on Germination and the Potassium and Calcium Content of Acacies Seeds. Seed Sci. Technol., 25: 45-57. 